ISSN :2085-6989

\title{
PERANCANGAN MULTIMEDIA PEMBELAJARAN INTERAKTIF DENGAN MENGGUNAKAN APLIKASI FLASH
}

Oleh :

\section{Zurnawita}

Staf Pengajar Jurusan Teknik Elektro Politeknik Negeri Padang

\section{ABSTRACT}

The rapid development of multimedia technology can be utilized by the world of education, particularly in improving the way of learning to the learning process can be developed and not left behind by technological advances. In this research the development of multimedia applications in education. This application provides an interactive material with animation, audio, video and comes with an evaluation form about the exercises. Results will be achieved of the media making this learning is that students can understand subjects of digital system. It is expected that these applications can facilitate the learning process improve the quality of teaching and learning achievement

Keywords : multimedia, interactive, learning, education, digital system

\section{PENDAHULUAN}

Pembelajaran yang sebelumnya dilakukan di dalam kelas pada umumnya dilakukan secara 1 arah yaitu pengajar memberikan bahan ajar kemudian siswa mendengarkan, kemudian metode pengajaran berubah, siswa tidak hanya sebagai obyek tetapi juga sebagai subyek sehingga peran pengajar sedikit berubah, tetapi kondisi belajar mengajar pada umumnya tidak berubah yaitu membaca, mendengar, dan melakukan praktek dan kondisi itu hanya bisa dilakukan disekolahan.

Menurut Dale (1969) (dikutip dari makalah Tugas Akhir Karnadi dkk), pada umumnya siswa hanya $10 \%$ mengingat dari apa yang mereka baca, $20 \%$ dari apa yang mereka dengar, 30\% dari apa yang mereka lihat, 50\% dari apa yang mereka dengar dan lihat, $70 \%$ dari apa yang mereka katakan dan tulis, dan $90 \%$ dari apa yang mereka katakan seperti yang mereka lakukan. Untuk itu dibutuhkan suatu media yang dapat digunakan sebagai buku (untuk dibaca), mengeluarkan suara (untuk pendengaran), perangkat latihan dan latihan soal sehingga siswa dapat membaca, mendengar, mencoba, serta berlatih dan mengukur kemampuan mereka, sehingga siswa tidak hanya belajar disekolah tetapi juga bisa dilakukan di rumah atau dimanapun mereka berada.

Seiring kemajuan teknologi terutama teknologi komunikasi dan informasi maka arah model dan pola pendidikan telah berubah. Penggunaan komputer sebagai alat bantu pengajaran sangat dimungkinkan terutama pada penggunaan aplikasi pengajaran berbasis multimedia dan berbasis web (internet) atau sering disebut dengan Pengajaran Berbantuan Komputer atau Computer Aided Instruction (CAI).

Salah satu perangkat lunak yang dapat digunakan untuk membuat aplikasi pembelajaran multimedia adalah Adobe Flash. Perangkat ini cukup mudah 
digunakan dan dapat menghasilkan karya multimedia yang menawan.

\section{Landasan Teori}

\section{Multimedia}

Multimedia adalah pemanfaatan komputer untuk membuat dan menggabungkan teks, grafik, audio, gambar bergerak (video dan animasi) dengan menggabungkan link yang memungkinkan pemakai melakukan navigasi, berinteraksi, berkreasi dan berkomunikasi. Dalam definisi ini terkandung empat komponen penting multimedia. Pertama, harus ada komputer yang mengkoordinasikan apa yang dilihat dan didengar. Kedua, harus ada link yang menghubungkan pemakai dengan informasi. Ketiga, harus ada alat navigasi yang membantu pemakai menjelajah jaringan informasi yang saling terhubung. Keempat, multimedia menyediakan tempat kepada pemakai untuk mengumpulkan, memproses, dan mengkomunikasikan informasi dengan ide. Jika salah satu komponen tidak ada, bukan multimedia dalam arti luas namanya. Misalnya, jika tidak ada komputer untuk berinteraksi, maka itu namanya media campuran, bukan multimedia. Kalau tidak ada alat navigasi yang memungkinkan untuk memilih jalannya suatu tindakan maka itu namanya film, bukan multimedia. Demikian juga kita tidak mempunyai ruang untuk berkreasi dan menyumbangkan ide sendiri, maka nama televisi, bukan multimedia. Dari beberapa definisi di atas, maka multimedia ada yang online (Internet) dan multimedia ada yang offline (tradisional)."

Pengguna atau lingkungan yang memanfaatkan multi media adalah

a. Multimedia dalam bisnis

Apliksi bisnis untuk multimedia meliputi presentasi, pelatihan, pemasaran, periklanan, demo produk, katalog, pesan kilat, dan komunikasi jaringan

b. Multimedia di sekolah

Aplikasi multi media pada tingkat sekolah biasanya berupa multimedia pembelajaran interaktif

c. Multimedia di rumah Aplikasi untuk mendisain rumah, interior, hiburan dan lain-lain

Tahapan-tahapan Pembuatan Proyek Multimedia diantaranya adalah

- Perencanaan dan pembiayaan

- Disain dan Produksi

- Pengujian

- Pengiriman

Peralatan yang digunakan dalam pembuatan multimedia adalah

- Perangkat keras

- Perangkat lunak

- Kreatifitas

- Organisasi

\section{Media Pembelajaran}

Ivan pada jurnalnya menuliskan Media pembelajaran memegang peranan penting dalam proses pembelajaran. Menurut Latuheru (1988 : 11), bahwa media adalah semua bentuk perantara yang digunakan oleh manusia untuk menyampaikan atau menyebar ide, sehingga hal yang dikemukakan itu bisa sampai pada penerima. Apabila media itu membawa pesan-pesan atau informasi yang bertujuan instruksional atau mengandung maksud-maksud pengajaran maka media itu disebut media pembelajaran. Manfaat media pembelajaran secara umum adalah untuk membantu siswa belajar secara optimal dan mempermudah interaksi pendidik dengan siswa itu sendiri sehingga tujuan belajar tercapai. Menurut Harjanto (1997 : 245) seperti yang dikutip oleh Kusumah (2009), manfaat media pembelajaran antara lain memperjelas penyajian pesan agar tidak terlalu verbalistis, mengatasi keterbatasan ruang, waktu dan daya indera, serta dapat 
menimbulkan persepsi yang sama terhadap suatu masalah

\section{Prosedur Pengembangan Multimedia} Pembelajaran

Dalam mengembangkan media pembelajaran berbasis multimedia interaktif diperlukan berbagai cara untuk menghasilkan media yang baik. Salah satunya adalah dengan menerapkan prosedur pengembangan media pembelajaran . Menurut Arief S. Sadiman (2006 : 100), pengembangan media pembelajaran terbagi dalam 6 langkah, yaitu: (1) Menganalisis kebutuhan dan karakteristik siswa, (2) Perumusan tujuan instruksional, (3) Perumusan butir-butir materi, (4) Mengembangkan alat pengukur keberhasilan, (5) Penulisan naskah media, dan (6) Mengadakan tes dan revisi. Menurut Criswell (1989 : 50) terdapat sepuluh tahap pengembangan multimedia pembelajaran, yaitu: (1) Conduct environmental analysis, (2) Conduct knowledge engineering, (3) Establish goals and instructional objectives, (4) Sequence topics and task, (5) Write courseware, (6) Design each frame, (7) Program the computer, (8) Produce accompanying documents, (9) Evaluate and revise, (10) Implement and follow up. Sedangkan menurut Luther (Ariesto Hadi Sutopo, 2003: 32 - 48) terdapat enam tahap sebagai langkah pengembangan multimedia pembelajaran, yaitu concept, design, material collecting, assembly, testing, dan distribution

\section{Adobe Flash CS3}

Adobe Flash CS3 adalah merupakan suatu aplikasi yang dapat digunakan untuk membuat suatu karya digital yang interaktif. Aplikasi ini secara luas digunakan untuk membuat aplikasi menawan yang mengandung video, gambar, suara, dan animasi. Aplikasi yang canggih dapat dibuat dengan menggunakan tool yang ada pada aplikasi flash, mengimport dari aplikasi adobe yang lain (adobe premiere, adobe photoshop dan lain-lain) juga dengan menggunakan action script. (Adobe Creative Team, 2007)

\section{Animasi}

Animasi pada dasarnya adalah gambar yang disusun secara berurutan sehingga ketika sekumpulan gambar ini dijalankan maka akan terlihat seperti gambar bergerak dengan satuan fps yang artinya butuh $\mathrm{n}$ gambar untuk menghasilkan animasi dalam 1 detik. Pada aplikasi Flash setiap gambar akan diletakkan pada 1 frame dan untuk menghasilkan animasi membutuhkan banyak gambar agar animasi terlihat halus.

\section{Action Script}

Action Script adalah bahasa skrip yang dimiliki Flash untuk menunjukkan koleksi set dari action, function, event dan event handler, sehingga dapat membuat aksi yang interaktif.

\section{Metode Penelitian}

Tujuan dari penelitian ini adalah perancangan multimedia pembelajaran interaktif dalam hal ini dikhususkan pada materi flip-flop. Penentuan materi ini didasarkan dari hasil ujian akhir prodi Teknik Komputer Jurusan Teknologi Informasi, dengan rincian soal sebagai berikut :

- Soal no 1 berisi tentang rangkaian ADDER

- Soal no 2 tentang definisi Clock dan jenisnya

- Soal no 3 tentang definisi Flipflop

- Soal no 4 tentang diagram pewaktuan dari flip-flop yang terpicu oleh clock

- Soal no 5 dan 6 berisi tentang aplikasi flip-flop 
Dari soal tersebut maka diketahui hasil

- Untuk soal no 2 dan 3 rata-rata keberhasilan menjawab hampir mencapai $100 \%$ berarti dapat disimpulkan kemampuan siswa memahami teori tentang flip-flop dan clock tidak bermasalah

- Untuk soal no 1 kemampuan rata-rata menjawab yaitu di bawah $30 \%$ yang berarti bahwa kemampuan siswa menyerap materi yang berhubungan dengan rangkaian ADDER sangat kurang (terutama tentang pemahaman 1 ADDER untuk mengolah 1 bit informasi)

- Untuk soal no 5 dan 6 kemampuan rata-rata menjawab yaitu di bawah $50 \%$ yang berarti bahwa kemampuan siswa untuk menyerap materi aplikasi flipflop masih kurang (terutama tentang cara kerja piranti)

Dari hasil di atas maka dapat diambil kesimpulan bahwa materi yang akan disuguhkan atau ditampilkan pada multimedia pembelajaran interaktif ini dititikberatkan pada pola kerja flip-flop, clock, serta rangkaian aplikasinya disertai dengan uraian singkat pada masing-masing materi sehingga diharapkan siswa dapat belajar mandiri sehingga lebih memahami materi flip-flop.

Kemudian setelah menentukan materi, langkah berikutnya adalah mengumpulkan bahan yang mendukung materi tersebut, setelah itu merancang bentuk aplikasi.

Rancangan bentuk aplikasi yang dibuat terlihat pada gambar 1

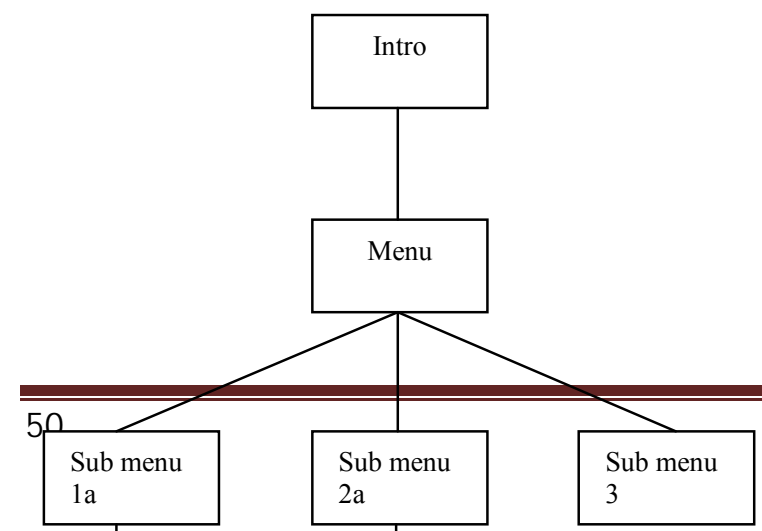

Gambar 1 Rancangan Aplikasi Multimedia Pembelajaran

Pada gambar 1 terlihat bahwa aplikasi akan diawali dengan tampilan intro, kemudian dilanjutkan dengan menampilkan menu dilanjutkan dengan sub menu 1,2 dan 3. Hal utama yang perlu diperhatikan dalam pembuatan aplikasi ini adalah pembagian setiap bagian pada adegan yang berbeda dan komponen yang digunakan pada adegan tersebut harus diletakkan pada layer yang berbeda. Hal ini dilakukan agar perbaikan sistem menjadi lebih mudah, jika semua bagian terletak pada adegan yang sama dan layer yang sama maka akan menimbulkan kesulitan ketika ingin melakukan perbaikan sistem.

\section{Hasil dan Pembahasan}

Setelah dirancang bentuk aplikasi secara umum maka langkah berikutnya adalah pembuatan rancangan antar muka.

Setiap perancangan antar muka aplikasi selalu disertai dengan uraian singkat tentang perilaku komponenkomponen yang ada didalamnya yang disebut dengan story board, seperti terlihat pada gambar 2. Hal ini dilakuka untuk memudahkan dalam pembuatan aplikasi pada Adobe Flash CS3. 


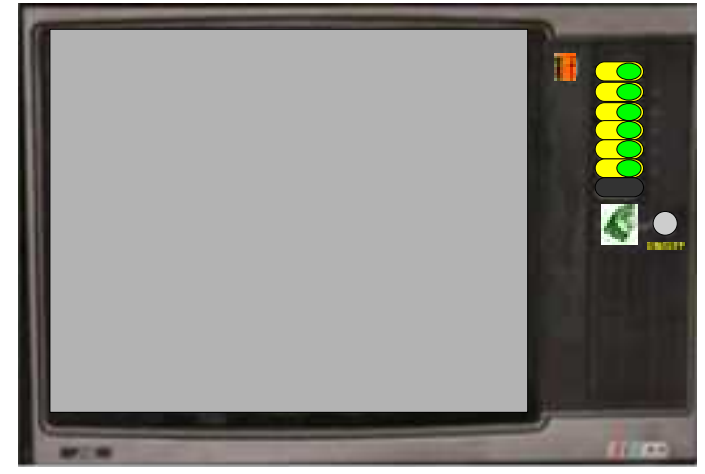

Gambar 2. Antar muka awal

Pada gambar 2 diperlihatkan rancangan antar muka awal (adegan 1), pada gambar tersebut terdapat 2 jenis tombol yang mempunyai perilaku, yaitu tombol on/off dan tombol menu. Tombol on/off mempunyai perilaku jika tombol mouse di tekan maka tampilan aplikasi akan menuju ke adegan 2 . Tombol menu pada adegan 1 ini hanya akan menimbulkan perubahan posisi jika tombol mouse di tekan. Pada story board untuk adegan 1 dapat diambil kesimpulan adalah sebagai berikut:

- Komponen aktif ada 2 jenis yaitu tombol on/off dan tombol menu

- Selain itu semua adalah komponen pasif

Dari kesimpulan tersebut maka implementasi pembuatan aplikasi pada aplikasi Flash adalah sebagai berikut (terlihat pada gambar 3)

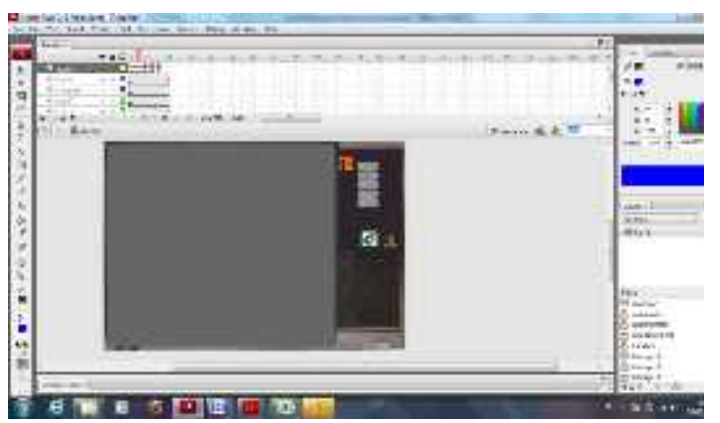

Gambar 3. Implementasi Rancangan Pada Flash
- Adegan 1 dibuat pada scene 1

- Scene 1 dibagi menjadi 6 layer, layer pertama untuk menampung komponen pasif (background), layer kedua untuk menampung komponen tombol on/ff dan layer ketiga sampai dengan ke 6 untuk tombol menu.

Pada tombol on/off maupun tombol menu pada awalnya adalah bentuk bangun biasa yang tidak dapat melakukan suatu aksi. Kemudian bangun tersebut diubah ke bentuk simbol, dalam hal ini simbol button. Setelah diubah menjadi simbol button maka tombol bisa diberi suatu aksi.

Pada gambar 4 diperlihatkan aplikasi proses flip-flop bekerja yang diimplementasikan pada flash.

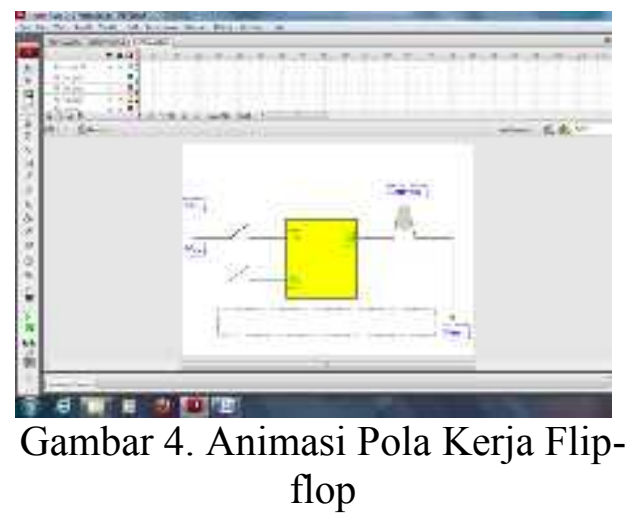

Pada gambar 4 digambarkan proses komponen flip-flop pada sisi input dan output, 1 kelompok komponen pasif dan 3 komponen aktif. Sehingga pada adegan ini terdapat minimal 4 layer. Komponen aktif pada adegan ini diubah ke dalam bentuk simbol movie clip, karena aksi yang akan dijalankan saling berkaitan antar komponen aktif sesuai dengan karakteristik komponen flip-flop, seperti jika saklar pada input $\mathrm{S}$ on dan saklar 
pada input $\mathrm{R}$ off maka ouput lampu akan menyala (terjadi perubahan warna dari grey menjadi kuning) Komponen aktif pada input $\mathrm{S}$ dan $\mathrm{R}$ selain diubah menjadi simbol juga diberi suatu nilai pada setiap aksinya sehingga dapat dikondisikan seperti yang diinginkan. Proses pengubahan komponen dilakukan secara interaktif oleh pengguna aplikasi dan dari setiap terjadi reaksi selalu meuncul komentar atau uraian singkat tentang hasil akhir prose padasehingga komponen flip-flop, sehingga diharapkan siswa dapat lebih memahami proses komponen flip-flop bekerja.

Pada adegan terakhir ditampilkan latihan soal dan rangkuman hasil latihan, sehingga siswa dapat mengukur tingkat pemahaman pada materi yang sudah ditampilkan, seperti terlihat pada gambar 5 dan gambar 6.

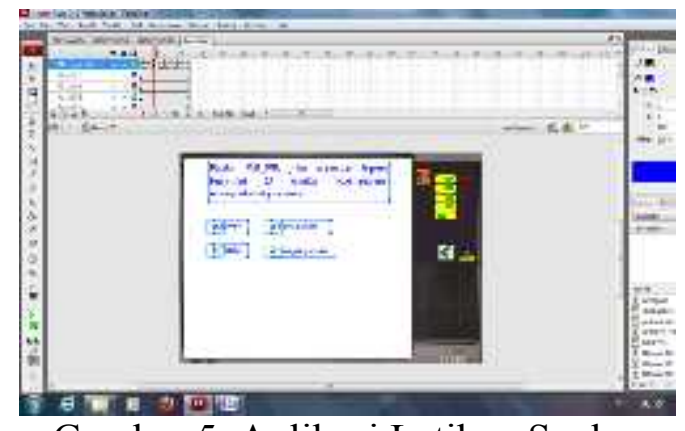

Gambar 5. Aplikasi Latihan Soal

Pada adegan yang diperlihatkan pada gambar 5 terdapat 1 komponen pasif berupa statik text dan 4 komponen aktif berupa simbol button. Setiap aksi dari komponen aktif mempunyai nilai yang dituliskan pada script di frame, 1 nilai betul dan 3 nilai salah yang akan dikalkulasikan pada frame terakhir yang menampilkan hasil akhir dari latihan seperti terlihat pada gambar 6 .

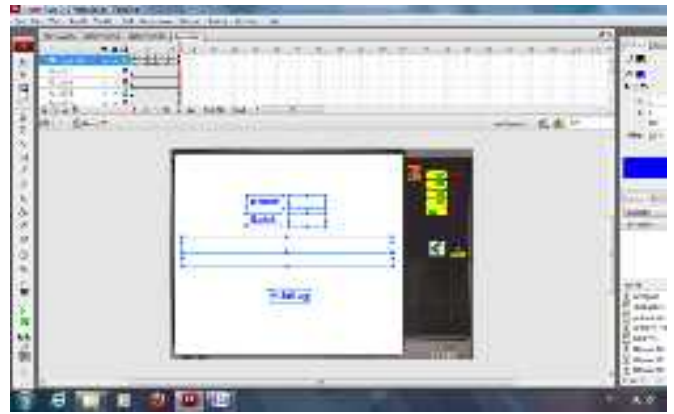

Gambar 6. Tampilan hasil akhir

Aplikasi yang akan dibuat pada dasarnya telah memenuhi kebutuhan media pembelajaran yang diperlukan siswa sehingga siswa dapat lebih memahami materi dikarenakan siswa dapat membaca, berlatih dan berinteraksi dengan aplikasi sehingga materi yang awalnya hanya berupa gambar mati dan tulisan diam maka dengan aplikasi ini siswa tidak hanya melihat gambar mati dan tulisan diam tetapi juga dapat berinteraksi dengan gambar dan melihat reaksi output karena perubahan input pada komponen flip-flop dan dilengkapi dengan komentar yang lebih memperkuat pemahaman materi.

\section{Penutup}

\section{Kesimpulan}

Dari penelitian yang telah dilakukan dapat di ambil kesimpulan sebagai berikut:

1. Pembuatan story board yang detail akan memudahkan dalam pembuatan aplikasi pada perangkat lunak Flash

2. Pembagian adegan dalam beberapa scene memudahkan pembuat sistem dalam melakukan perbaikan system

3. Pengguna dapat mengukur kemampuan pemahaman materi flip-flop dengan latihan yang ada pada sistem

\section{Saran}

Aplikasi ini akan lebih sempurna jika diujikan kepada siswa dengan cara 


\begin{abstract}
diberikan secara cuma-cuma pada siswa sebagai tambahan media pembelajaran sehingga siswa dapat belajar di rumah dan pengajar dapat mengukur perkembangan kemampuan siswa terutama pada materi flip-flop.
\end{abstract}

\title{
Daftar Pustaka
}

Arif Sadiman., dkk. (2003). Media

Pendidikan (Pengertian

Pengembangan

danPemafaatannya). Jakarta:

CV Rajawali

Irvan Rizkiansyah, Totok

Sukardiyono, M.T.,

Pengembangan Aplikasi

Pembelajaran Interaktif

Teknik Bermain Piano

Berbasis Multimediadi

Lembaga Kursus Musik

"Ethnictro" Yogyakarta

Latuheru, JD. (1988). Media

Pembelajaran dalam Proses

Belajar Masa. Kini. Jakarta:

Depdikbud Dirjen PT.Proyek

Pengenmbangan LPTK 